OPEN ACCESS

Edited by:

Chunfu Zheng,

Fujian Medical University, China

Reviewed by:

Renfeng $L i$,

Virginia Commonwealth University,

United States

Guorong Sun,

Hannover Medical School, Germany

*Correspondence:

Xueling Fang

1191012@zju.edu.cn

${ }^{t}$ These authors have contributed equally to this work

Specialty section: This article was submitted to Viral Immunology, a section of the journal

Frontiers in Immunology

Received: 18 October 2020 Accepted: 04 January 2021

Published: 25 February 2021

Citation:

Huang L, Zhang X and Fang X (2021) Case Report: Epstein-Barr Virus Encephalitis Complicated With Brain Stem Hemorrhage in an Immune-Competent Adult.

Front. Immunol. 12:618830. doi: 10.3389/fimmu.2021.618830

\section{Case Report: Epstein-Barr Virus Encephalitis Complicated With Brain Stem Hemorrhage in an Immune- Competent Adult}

\author{
Lingtong Huang $^{1+}$, Xuan Zhang $^{2 \dagger}$ and Xueling Fang ${ }^{1 *}$ \\ 1 Department of Critical Care Units, The First Affiliated Hospital, Zhejiang University School of Medicine, Hangzhou, China, \\ 2 Department of Infectious Disease, The First Affiliated Hospital, Zhejiang University School of Medicine, Hangzhou, China
}

Encephalitis caused by Epstein-Barr virus infection is uncommon, but most patients have a good outcome after symptomatic treatment. The infiltration of mononuclear cells in blood vessels and necrosis resulting from the immune response to Epstein-Barr virus infection in a very small number of patients seem to be the main cause of death. We describe a fatal case of Epstein-Barr virus encephalitis diagnosed by next-generation sequencing in an immune-competent adult but progressed to brainstem hemorrhage.

Keywords: Epstein-Barr virus, encephalitis, brainstem hemorrhage, next-generation sequencing, vasculitis

\section{INTRODUCTION}

Epstein-Barr virus (EBV) encephalitis is a rare type of viral encephalitis that is associated with hematopoietic stem cell transplantation $(1,2)$, solid organ transplant (3), and HIV infection (4-7). It usually occurs in children $(8,9)$, but it has also been reported in a few immune-competent adults (10). EBV encephalitis typically has a good prognosis $(6,11-13)$, and very few patients develop serious neurological sequelae (14) or die (15). However, EBV encephalitis is difficult to diagnose because its clinical manifestations are complex and diverse. Most patients with EBV encephalitis are admitted to the hospital due to mental symptoms (15). EBV encephalitis usually occurs in the brain stem $(9,12,16,17)$, cerebellum (9), thalamus (18), basal ganglia (12), optic nerve $(8,12)$, and spinal cord (12). The most frequent clinical features of EBV encephalitis are mental deterioration (19), reversible parkinsonism $(20,21)$, vasculitis $(4,9,15)$, and bleeding $(3,9)$.

In adults, there are no reports of brainstem hemorrhage caused by EBV encephalitis before. Here, we describe the first fatal case of EBV encephalitis diagnosed by next-generation sequencing (NGS) in an immune-competent adult and soon progressed to brainstem hemorrhage.

\section{CASE REPORT}

A 59-year-old man developed dizziness and fever (maximum body temperature, $39.0^{\circ} \mathrm{C}$ ) 6 days ago without obvious causes and was not given any treatment. He developed several seizures 1 day ago and was brought to the emergency department (ED) of our hospital by his family, as shown in the timeline in Figure 1. The patient was in good health, had not traveled, and had no history of taking medication before, and he did not drink or smoke. 


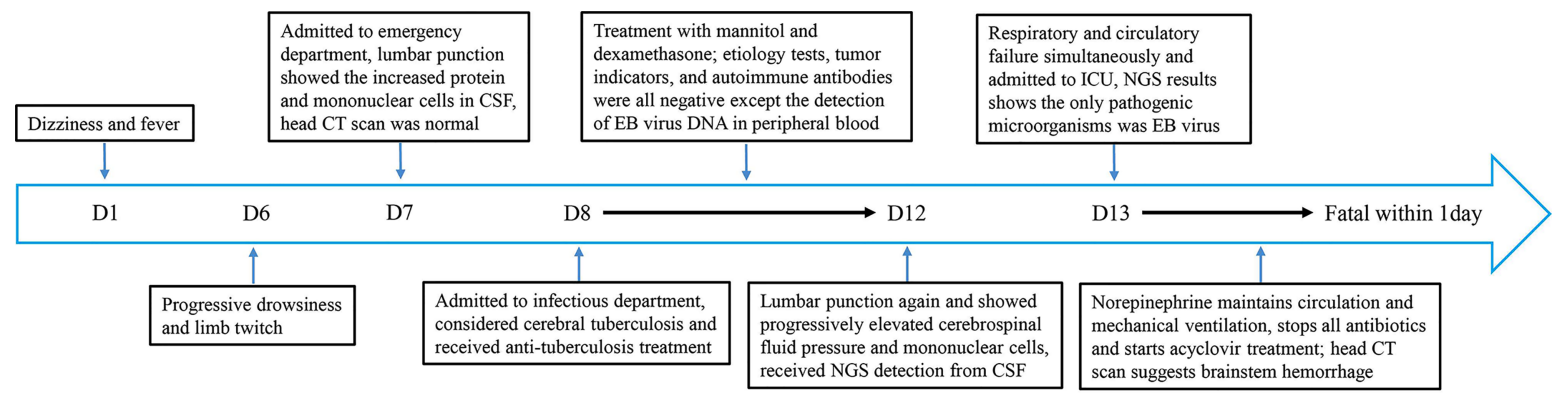

FIGURE 1 | Timeline depicting the disease course of the patient. The timeline illustrates the different events in the course of the patient's treatment and disease progression.

When he was brought to the ED, he was still unconscious and had a GCS score of E3V1M3 and meningeal irritation signs. An initial lab exam showed normal liver chemistry, kidney chemistry, and infection parameters (CRP $4.7 \mathrm{mg} / \mathrm{L}$; PCT 0.13 $\mathrm{ng} / \mathrm{ml}$; ESR, $3 \mathrm{~mm} / \mathrm{h}$ ) (Table 1). There was no other evidence to prove the existence of infection, except for the fever. We performed a lumbar puncture under normal open pressure. The cerebrospinal fluid (CSF) pressure was $250 \mathrm{~mm} \mathrm{H}_{2} \mathrm{O}$, and CSF was colorless and not turbid. Analysis of CSF showed a red blood cell count of $12 \times 10^{6} / \mathrm{L}$ and a mononuclear cell count of $28 \times 10^{6} / \mathrm{L}$ (75\% lymphocytes and $25 \%$ monocytes) (Table 1). CSF chemistry showed that the protein content increased to $1.982 \mathrm{~g} / \mathrm{L}$ (normal value, $0.15-0.45 \mathrm{~g} / \mathrm{L}$ ), and the glucose and the $\mathrm{Cl}^{-}$levels were normal. A head CT scan showed no abnormal signs (Figure 2), and an abdomen CT scan was not indicative of liver or spleen enlargement.

The patient was transferred from the ED to the infection department, and cerebral tuberculosis was suspected. Over the next three days, he was administered anti-tuberculosis treatment, moxifloxacin for anti-infection treatment, and mannitol three times a day to reduce intracranial pressure. Additionally, autoimmune encephalitis was suspected, and the patient was intravenously administered $10 \mathrm{mg}$ dexamethasone. A series of blood tests conducted over the next three days revealed negative results for the T-spot test, cytomegalovirus DNA, bacteria assay (blood culture and cerebrospinal fluid culture), fungal assay (Cryptococcus neoformans antigen assay), virus assay in the blood (hepatitis A, hepatitis B, hepatitis C, hepatitis D, Cytomegalovirus, and herpes simplex virus), autoantibodies (antinuclear antibody, double-stranded DNA, soluble nuclear protein antibody, RNP, Sm, SSa, ssa52, anti-SSB, anti-Scl-70, anti-PM-scl, anti-JO-1, centromere antibody, anti-PCNA, small nuclear body antibody, Rib, APS-related antibody, antimitochondrial antibody, IgG4, MPO, ANCA, and anti- $N$ methyl-D-aspartate antibody), and tumor markers (AFP, CEA, CA125, CA199, ferritin, and prostate-specific antigen). The EBV DNA detected with primers targeting BamHI-W was 1,300 copies/ml in blood, anti-EBV capsid antigen IgM was negative, and anti-EBV capsid antigen IgG was positive blood. The patient's CRP levels were normal, and PCT levels were below $0.5 \mathrm{ng} / \mathrm{ml}$.

On the fourth day of hospitalization, the patient was still unconscious. Lumbar puncture was performed again under normal opening pressure. Additionally, pathogen detection in the CSF was performed by NGS. The NGS detection method was the same as we described before (22). The measured CSF pressure was $310 \mathrm{~mm} \mathrm{H}_{2} \mathrm{O}$, and the CSF was still colorless and not turbid. Analysis of CSF revealed a red blood cell count of $30 \times 10^{6} / \mathrm{L}$, an increase in the mononuclear cell count to $200 \times 10^{6} / \mathrm{L}(70 \%$ of lymphocytes), a decrease of protein content to $1.010 \mathrm{~g} / \mathrm{L}$, and normal glucose and $\mathrm{Cl}^{-}$levels.

On the fifth day of hospitalization, circulatory failure and a decrease in oxygen saturation were observed, and the patient was transferred to the intensive care unit (ICU) with a GCS score of E1V1M3. After transfer to the ICU, tracheal intubation was performed. The NGS results showed that the CSF was positive for the EBV (Figure 3) and negative for fungi, bacteria, and parasites. These findings were indicative of EBV encephalitis. Therefore, all antibiotic treatments were discontinued, and $0.5 \mathrm{~g}$ acyclovir was intravenously administered three times a day.

TABLE 1 | Summary of inflammatory markers and CSF examination during the whole hospitalization course.

Temp ( $\left.{ }^{\circ}\right)$ WBC (10^9/L) CRP (mg/L) PCT (ng/ml)
Examination of Cerebrospinal Fluid

Protein (g/L) Glu (mmol/L) $\quad \mathrm{Cl}^{-}(\mathrm{mmol} / \mathrm{L})$ Pressure $\left(\mathrm{mmH}_{2} \mathrm{O}\right)$ Mononuclear cell $\left(10^{\wedge} 6 / \mathrm{L}\right)$

\begin{tabular}{|c|c|c|c|c|c|c|c|c|c|}
\hline HD1 & 36.4 & 10.8 & 4.7 & 0.13 & 1.982 & 2.4 & 112 & 250 & 28 \\
\hline HD2 & 38.4 & 9.1 & 10.3 & 0.2 & 1.087 & 3.4 & 117 & 250 & 130 \\
\hline HD3 & 37.1 & 13 & / & I & / & / & / & / & / \\
\hline HD4 & 38.6 & 11.2 & / & / & 1.010 & 4 & 114 & 310 & 200 \\
\hline HD5 & 38.8 & 12.7 & 58.3 & 0.26 & / & / & I & / & / \\
\hline HD6 & 37.8 & 12.5 & 54.9 & 0.24 & / & / & / & / & / \\
\hline
\end{tabular}

HD, hospitalization day; Temp, Temperature; WBC, white blood cell; CRP, C-reactive protein; PCT, procalcitonin. 

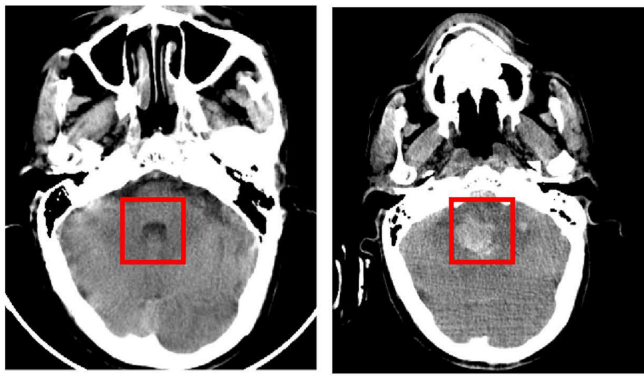

Medulla

Oblongata
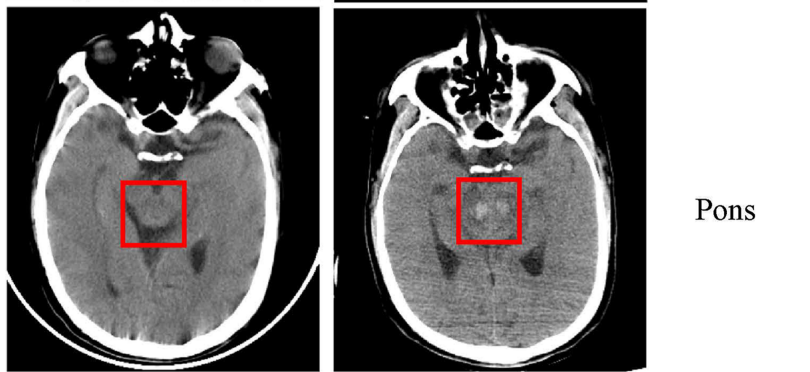

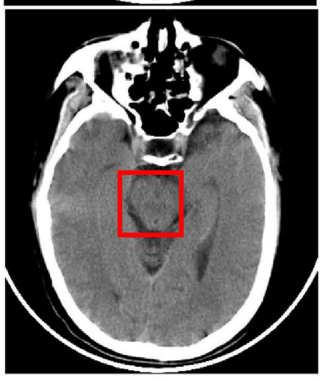

Head CT scan in ED

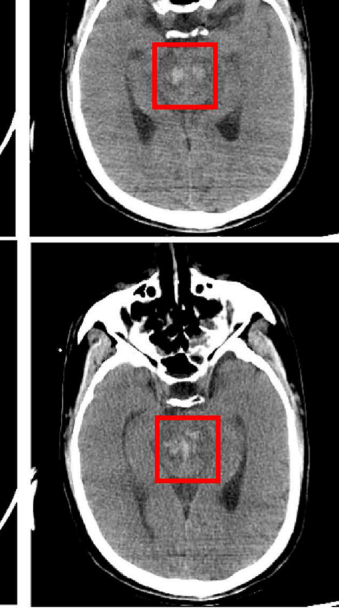

Head CT scan in ICU

Pons

Pons,

close to midbrain

FIGURE 2 | Head CT scan in the ED and ICU. Head CT scan showing that as the disease progressed within five days, the patient had extensive bleeding from the medulla oblongata to the pons as marked in the figure.

After the patient was stable, a head CT examination was performed that revealed a massive hemorrhage in the brainstem that could not be surgically removed (Figure 2). The patient's blood pressure dropped again within 1 day of admission to the ICU, and this was accompanied by a decrease in oxygen saturation and unequal pupil size. Soon after, the patient succumbed to the fatalities.

\section{DISCUSSION}

In this study, we describe a rare case of an immune-competent patient with EBV encephalitis in whom the intracranial pressure continued to increase progressively despite mannitol treatment. The case was complicated by brainstem hemorrhage in a short time, and the patient eventually died. In this case, cancer, other pathogen infections, autoimmune encephalitis, and other conditions were ruled out, and NGS showed that the CSF was positive for EBV DNA. Therefore, EBV encephalitis was diagnosed.

As described in previously reported cases of EBV encephalitis (6, 17-19), CSF pressure, mononuclear cell count, and protein content in the CSF increased after infection onset, but the glucose and $\mathrm{Cl}^{-}$levels were normal which was also observed in this case. EBV encephalitis has no typical symptoms, and the results of CSF examination are similar to those for cerebral tuberculosis (4, 12). The presence of EBV DNA in the blood is very common in hospitalized patients (clinically relevant cutoff value $=2,000$ copies/ml) (23), so we did not consider EBV encephalitis for the viral load of 1,300 copies/ml at the beginning. Therefore, in this case, it is inevitable that the patient was initially misdiagnosed before the NGS results were obtained. Some patients also test positive for autoantibodies such as the anti$\mathrm{N}$-methyl-D-aspartate antibody (24), and as a result, anti-Nmethyl-D-aspartate receptor encephalitis was diagnosed $(25,26)$. In this case, however, the results of anti- $N$-methyl-D-aspartate antibody were negative.

In most cases, EBV encephalitis is accompanied by liver and spleen enlargement $(15,27)$. However, some patients may not have an enlarged liver and spleen (19), which provides a challenge for diagnosing EBV encephalitis. In the early stage of the disease, CT does not show abnormalities, and MRI examinations often show increased signal intensity on T2weighted imaging sequences on both temporal lobes $(12,15$, $19,28)$. In the present case, the CT images did not show any abnormalities, except for the CT scan taken later that showed cerebral hemorrhage. For suspected intracranial infection or autoimmune encephalitis, an MRI examination is necessary. MRI examination can indicate viral encephalitis, but imaging examination cannot pinpoint the exact pathogen for us. Due to the patient's consciousness disturbance when admitted to ED, it is impossible to inquire whether the patient has metal implants, and the MRI examination is extremely risky. Besides, the patient has been given monitoring measures, including ECG monitors in ED and infection department, so we could not perform MRI.

The autopsy results of patients who died of EBV encephalitis show mononuclear cell infiltrates in the perivascular and necrotic hemorrhagic focus in the brain $(9,15,29)$. Therefore, the pathogenesis of EBV encephalitis is more inclined towards inflammation caused by the immune response rather than the

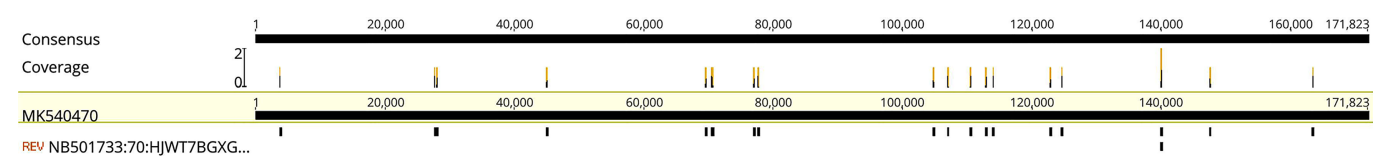

FIGURE 3 | Mapping results of EBV reads in cerebrospinal fluid (CSF). Mapping results of EBVs in the CSF to EBV reference genome MK540470. 
virus itself (30), and most patients with EBV encephalitis are treated with intravenous immunoglobulins (31) and steroids (15, $21)$. Currently, ganciclovir $(6,13,27)$ and acyclovir $(21,27)$ are often used for treatment, but there is no standard treatment strategy for EBV encephalitis. Although we used steroids before diagnosing EBV encephalitis, we were still unable to prevent the disease's rapid progression. EBV encephalitis may be a selflimiting disease (32), and no double-blind, randomized controlled clinical trial has proven the effectiveness of these drugs. The only treatment that can eliminate EBV infection is hematopoietic stem cell transplantation (33), but this can be very difficult to practice.

In the present case, the patient was admitted to the hospital because of neurological symptoms, but a head CT scan taken at the admission time showed no abnormalities. The patient's condition continued to deteriorate during hospitalization, and brainstem hemorrhage occurred on the fifth day. The patient's condition was similar to that described in a child: extensive bleeding points appeared in the brain stem after EBV encephalitis (9). In this case, we speculate that the brainstem hemorrhage may be related to EBV-induced vasculitis, which ultimately led to simultaneous failure of the patient's breathing and circulation. The limitation of this case is that we cannot perform an autopsy to confirm it, and we can only speculate by CT findings and the increasing number of mononuclear cells in CSF.

Although the patient died quickly in the end, we believe that NGS testing may become an effective means to rule out nonviral infections such as fungi, bacteria, tuberculosis, and some parasites. At the same time, after rule out the possibility of tumors, steroids and intravenous immunoglobulins seem to be an effective salvage treatment in some critical care patients. There are many challenges for NGS, including data analysis, expensive cost, and time required. In this case, NGS's turnaround time was $24 \mathrm{~h}$, and the cost was approximately 300 dollars. Actually, in our hospital, EBV qPCR is only tested once a day in the morning, so qPCR's turn-around time still needs $24 \mathrm{~h}$. Besides, except EBV, we have to determine the presence of Herpes simplex virus, Cytomegalovirus, and other viral DNA if we use qPCR to identify the pathogenic microorganisms in CSF, and the cost was approximately 200 dollars, which is similar to the NGS test. Therefore, in our view, NGS is an acceptable test for critically ill patients with unknown pathogens. It should be noted that if blood vessels are damaged during lumbar puncture, the harvested cerebrospinal fluid samples may be contaminated with EBV DNA from the blood. During the NGS test, the specimen will be centrifuged to reduce the impact of its own DNA, so we can only retrospectively get the results of free DNA in the patient's cerebrospinal fluid. Single-cell sequencing of cerebrospinal fluid to determine what changes have occurred in the immune cells of CSF may help us clarify the pathogenesis of EBV encephalitis and possible therapeutic targets. Finally, the patient's family refused the autopsy, and we could not get the pathological results to get the most direct evidence of EBV infection in the brain, which was the limitation of this case.

In conclusion, this is the first reported case of EBV encephalitis complicated by brainstem hemorrhage in an immune-competent adult who eventually succumbed to the fatalities. Based on the findings, it is recommended that in patients with signs of encephalitis, NGS of CSF be used to quickly rule out the diagnosis of encephalitis caused by other pathogenic microorganisms and confirm the diagnosis of EBV encephalitis. Simultaneously, start intravenous immunoglobulins and steroid therapy as soon as possible may be beneficial to patients with life-threatening EBV encephalitis.

\section{DATA AVAILABILITY STATEMENT}

The original contributions presented in the study are included in the article/supplementary material. Further inquiries can be directed to the corresponding author.

\section{ETHICS STATEMENT}

The studies involving human participants were reviewed and approved by Ethics Committee of the First Affiliated Hospital of Zhejiang University. The patients/participants provided their written informed consent to participate in this study.

\section{AUTHOR CONTRIBUTIONS}

$\mathrm{LH}$ and $\mathrm{XZ}$ wrote the case report, drafted the manuscript, and prepared the figures. XF critically reviewed the final manuscript. All authors contributed to the article and approved the submitted version.

\section{FUNDING}

The work was supported by the National Science \& Technology Major Project of China (grant \#2017ZX10204401 to XZ) and Zhejiang Provincial Natural Science Foundation of China (grant \#LQ19H190001 to XZ). The funders had no role in the decision to publish or prepare the manuscript. We thank Dr. Xia Jin from IngeniGen XunMinKang Biotechnology Inc. for her work on NGS data processing and analysis in this manuscript. 


\section{REFERENCES}

1. Martelius T, Lappalainen M, Palomaki M, Anttila VJ. Clinical characteristics of patients with Epstein Barr virus in cerebrospinal fluid. BMC Infect Dis (2011) 11:281. doi: 10.1186/1471-2334-11-281

2. Schmidt-Hieber M, Schwender J, Heinz WJ, Zabelina T, Kuhl JS, Mousset S, et al. Viral encephalitis after allogeneic stem cell transplantation: a rare complication with distinct characteristics of different causative agents. Haematologica (2011) 96:142-9. doi: 10.3324/haematol.2010.029876

3. Babik JM, Katrak S, Miller S, Shah M, Chin-Hong P. Epstein-Barr virus encephalitis in a renal transplant recipient manifesting as hemorrhagic, ringenhancing mass lesions. Transpl Infect Dis (2015) 17:744-50. doi: 10.1111/ tid. 12431

4. Raman L, Nelson M. Cerebral vasculitis and encephalitis due to Epstein-Barr virus in a patient with newly diagnosed HIV infection. J Clin Virol (2014) 59:264-7. doi: 10.1016/j.jcv.2014.01.018

5. Trevillyan JM, Mahony AA, Mclean C, Hoy JF. Successful treatment of Epstein-Barr virus encephalitis in the setting of HIV-associated neurocognitive disorder: a diagnostic and therapeutic challenge. Antivir Ther (2013) 18:257-61. doi: 10.3851/IMP2451

6. Katramados AM, Sripathi N, Brar I, Mitsias PD. Intravenous ganciclovir consistently induces remission of persistent Epstein-Barr encephalitis in an HIV-1-infected patient. AIDS (2007) 21:778-80. doi: 10.1097/QAD. 0b013e3280b07784

7. Skiest DJ. Focal neurological disease in patients with acquired immunodeficiency syndrome. Clin Infect Dis (2002) 34:103-15. doi: 10.1086/ 324350

8. Bazzino Rubio F, Gonzalez Betlza M, Gonzalez Rabelino G, Bello Pedrosa O. Optic neuritis following Epstein-Barr virus encephalitis in immunocompetent children: A case report. Neurologia (2017) 32:129-31. doi: 10.1016/ j.nrl.2015.03.016

9. Hofer M, Weber A, Haffner K, Berlis A, Klingel K, Kruger M, et al. Acute hemorrhagic leukoencephalitis (Hurst's disease) linked to Epstein-Barr virus infection. Acta Neuropathol (2005) 109:226-30. doi: 10.1007/s00401-0040930-3

10. Koning MT, Brik T, Hagenbeek R, Van Den Wijngaard I. A case of fulminant Epstein-Barr virus encephalitis in an immune-competent adult. J Neurovirol (2019) 25:422-5. doi: 10.1007/s13365-018-0718-1

11. Zhang S, Feng J, Shi Y. Transient widespread cortical and splenial lesions in acute encephalitis/encephalopathy associated with primary Epstein-Barr virus infection. Int J Infect Dis (2016) 42:7-10. doi: 10.1016/j.ijid.2015.11.009

12. Phowthongkum P, Phantumchinda K, Jutivorakool K, Suankratay C. Basal ganglia and brainstem encephalitis, optic neuritis, and radiculomyelitis in Epstein-Barr virus infection. J Infect (2007) 54:e141-4. doi: 10.1016/ j.jinf.2006.09.007

13. Garamendi I, Montejo M, Cancelo L, Lopez L, Aguirrebengoa K, Martin A, et al. Encephalitis caused by Epstein-Barr virus in a renal transplant recipient. Clin Infect Dis (2002) 34:287-8. doi: 10.1086/323008

14. Kalita J, Maurya PK, Kumar B, Misra UK. Epstein Barr virus encephalitis: clinical diversity and radiological similarity. Neurol India (2011) 59:605-7. doi: 10.4103/0028-3886.84347

15. Francisci D, Sensini A, Fratini D, Moretti MV, Luchetta ML, Di Caro A, et al. Acute fatal necrotizing hemorrhagic encephalitis caused by Epstein-Barr virus in a young adult immunocompetent man. J Neurovirol (2004) 10:414-7. doi: $10.1080 / 13550280490521050$

16. Jubelt B, Mihai C, Li TM, Veerapaneni P. Rhombencephalitis / brainstem encephalitis. Curr Neurol Neurosci Rep (2011) 11:543-52. doi: 10.1007/ s11910-011-0228-5

17. Shian WJ, Chi CS. Fatal brainstem encephalitis caused by Epstein-Barr virus. Pediatr Radiol (1994) 24:596-7. doi: 10.1007/BF02012744

18. Johkura K, Momoo T, Kuroiwa Y. Thalamic involvement of Epstein-Barr virus encephalitis demonstrated by MRI. J Neurol (2003) 250:357-8. doi: 10.1007/s00415-003-0977-4
19. Kim JH, Joo BE, Koh SB. Serial diffusion-weighted MR imaging findings in a patient with Epstein-Barr virus encephalitis. J Neurol (2007) 254:1616-8. doi: 10.1007/s00415-007-0619-3

20. Guan J, Lu Z, Zhou Q. Reversible parkinsonism due to involvement of substantia nigra in Epstein-Barr virus encephalitis. Mov Disord (2012) 27:156-7. doi: 10.1002/mds.23935

21. Roselli F, Russo I, Fraddosio A, Aniello MS, De Mari M, Lamberti P, et al. Reversible Parkinsonian syndrome associated with anti-neuronal antibodies in acute EBV encephalitis: a case report. Parkinsonism Relat Disord (2006) 12:257-60. doi: 10.1016/j.parkreldis.2005.11.004

22. Fang $\mathrm{X}, \mathrm{Xu}$ M, Fang Q, Tan $\mathrm{H}$, Zhou J, Li Z, et al. Real-time Utilization of Metagenomic Sequencing in the Diagnosis and Treatment Monitoring of an Invasive Adenovirus B55 Infection and Subsequent Herpes Simplex Virus Encephalitis in an Immunocompetent Young Adult. Open Forum Infect Dis (2018) 5:ofy114. doi: 10.1093/ofid/ofy114

23. Stevens SJ, Vervoort MB, Van Den Brule AJ, Meenhorst PL, Meijer CJ, Middeldorp JM. Monitoring of epstein-barr virus DNA load in peripheral blood by quantitative competitive PCR. J Clin Microbiol (1999) 37:2852-7. doi: 10.1128/JCM.37.9.2852-2857.1999

24. Linnoila JJ, Binnicker MJ, Majed M, Klein CJ, Mckeon A. CSF herpes virus and autoantibody profiles in the evaluation of encephalitis. Neurol Neuroimmunol Neuroinflamm (2016) 3:e245. doi: 10.1212/NXI.0000000 000000245

25. Danieli D, Moraes ACM, Alves MP, Dutra LA, Hoftberger R, Barsottini OGP, et al. Anti-N-methyl-D-aspartate receptor encephalitis and Epstein-Barr virus: another tale on autoimmunity? Eur J Neurol (2017) 24:e46-7. doi: 10.1111/ene.13332

26. Garre J, Sprengers M, Van Melkebeke D, Laureys G. EBV-NMDA double positive encephalitis in an immunocompromised patient. J Neurol Sci (2019) 396:76-7. doi: 10.1016/j.jns.2018.11.001

27. Dagdemir A, Tasdemir HA, Dilber C, Gok F, Kubar A. Increased intracranial pressure due to chronic active Epstein-Barr virus infection. Pediatr Neurol (2006) 35:352-5. doi: 10.1016/j.pediatrneurol.2006.05.014

28. Misra UK, Kalita J, Phadke RV, Wadwekar V, Boruah DK, Srivastava A, et al. Usefulness of various MRI sequences in the diagnosis of viral encephalitis. Acta Trop (2010) 116:206-11. doi: 10.1016/j.actatropica.2010.08.007

29. Hausler M, Ramaekers VT, Doenges M, Schweizer K, Ritter K, Schaade L. Neurological complications of acute and persistent Epstein-Barr virus infection in paediatric patients. J Med Virol (2002) 68:253-63. doi: 10.1002/ jmv.10201

30. Schellinger PD, Sommer C, Leithauser F, Schwab S, Storch-Hagenlocher B, Hacke W, et al. Epstein-Barr virus meningoencephalitis with a lymphoma-like response in an immunocompetent host. Ann Neurol (1999) 45:659-62. doi: 10.1002/1531-8249(199905)45:5<659::aid-ana16>3.0.co;2-9

31. D'ambrosio E, Khalighinejad F, Ionete C. Intravenous immunoglobulins in an adult case of post-EBV cerebellitis. BMJ Case Rep (2020) 13(2):e231661. doi: 10.1136/bcr-2019-231661

32. Koskiniemi M, Korppi M, Mustonen K, Rantala H, Muttilainen M, Herrgard E, et al. Epidemiology of encephalitis in children. A prospective multicentre study. Eur J Pediatr (1997) 156:541-5. doi: 10.1007/s004310050658

33. Kimura H, Cohen JI. Chronic Active Epstein-Barr Virus Disease. Front Immunol (2017) 8:1867. doi: 10.3389/fimmu.2017.01867

Conflict of Interest: The authors declare that the research was conducted in the absence of any commercial or financial relationships that could be construed as a potential conflict of interest.

Copyright $\odot 2021$ Huang, Zhang and Fang. This is an open-access article distributed under the terms of the Creative Commons Attribution License (CC BY). The use, distribution or reproduction in other forums is permitted, provided the original author(s) and the copyright owner(s) are credited and that the original publication in this journal is cited, in accordance with accepted academic practice. No use, distribution or reproduction is permitted which does not comply with these terms. 